\title{
Richard Havel, Howard Eder, and the evolution of lipoprotein analysis
}

\author{
Scott M. Grundy
}

University of Texas Southwestern Medical Center, Dallas, Texas, USA.

\begin{abstract}
In 1956, the JCI published a paper by Richard Havel, Howard Eder, and Joseph Bragdon on a method using an ultracentrifuge to physically separate plasma lipoproteins and chemical methods to analyze their lipid constituents. This paper has been much cited (7081 times as of this writing) in part because it represents a solid method that, with various modifications, has been applicable for the study of lipoproteins for almost half a century.
\end{abstract}

The paper (1) marked a milestone in the long and distinguished career of Eder, who remained particularly interested in one of the lipoprotein fractions, HDL. Eder died earlier this year at the age of 86 . He was a close friend of mine, and I greatly admired his good will and perspective. He became a wonderful father figure to researchers in the lipoprotein field. Bragdon was a pathologist whose primary interest was the pathogenesis of atherosclerosis; he did not develop a career in lipoprotein research. Havel (Figure 1), on the other hand, continued in lipoprotein research and emerged as one of the pioneering giants of the field. The study's rigor reflects Havel's characteristic clear thinking and his attention to detail. He maintains a keen interest in lipoprotein metabolism to this day - whenever I am stumped about a thorny problem in human metabolism, I always seek Dick's counsel; he never fails to provide acute and illuminating insights.

The research behind the paper (1) was carried out at the Heart Institute, now called the National Heart, Lung, and Blood Institute (NHLBI). These investigators were part of a first generation of lipid/lipoprotein researchers from a team assembled by Christian Anfinsen. Among others in this group were Daniel Steinberg, Robert Gordon, DeWitt Goodman (a former editor-in-chief of the JCI), and Donald Fredrickson. A host of second- and third-generation researchers, the progeny of these original investiga-

Nonstandard abbreviations used: CHD, coronary heart disease; $S$, Svedberg sedimentation units; $\mathrm{S}_{\mathrm{f}}, \mathrm{S}$ in reverse.

Conflict of interest: The author has declared that no conflict of interest exists.

Citation for this article: J. Clin. Invest. 114:1034-1037 (2004). doi:10.1172/JCI200423198. tors, have populated the lipoprotein field and have generated much of our current knowledge of lipoproteins.

The lipoprotein field was relatively new when Havel, Eder, and Bragdon published their paper. Hints of lipid-protein complexes in plasma emerged during the first quarter of the 20th century $(2,3)$. Over the next 25 years, their existence and their heterogeneity became an established fact. Two distinct classes of lipid-containing proteins were identified through alcohol/lowsalt fractionation of plasma (4). In 1941, $\alpha$ - and $\beta$-migrating lipids were found by electrophoresis of human plasma (5). Then, in $1945, \beta$-migrating lipoproteins were isolated by ultracentrifugal flotation (6). Shortly afterwards, John Gofman and Frank Lingren, two physical chemists at Donner Laboratory at Berkeley, exploded onto the scene and carried out an amazing series of

investigations into characteristics of human plasma lipoproteins. These investigators and their colleagues used a combination of preparative and analytical ultracentrifugation for the study of lipoproteins (7-11). Combining genius with energy, these investigators, in a few short years, defined the major lipoprotein classes and described many of their main features. They used several preparative ultracentrifuges running around the clock to isolate samples for analytical ultracentrifugation. They measured lipoprotein levels in large numbers of people and found important associations with the presence of coronary heart disease (CHD). Their hypothesis that different lipoprotein fractions vary in atherogenic potential immediately ignited a dispute that has never been fully resolved but energized the development of a whole new field.

Gofman et al. (7-11) classified lipoproteins based on their flotation characteristics (Svedberg sedimentation units $[\mathrm{S}]$ in reverse $\left[\mathrm{S}_{\mathrm{f}}\right]: d<1.006 \mathrm{~g} / \mathrm{ml}\left[\mathrm{S}_{\mathrm{f}}>20\right]$; $d=1.006-1.019 \mathrm{~g} / \mathrm{ml}\left[\mathrm{S}_{\mathrm{f}} 12-20\right] ; d=1.019$ $1.063 \mathrm{~g} / \mathrm{ml}\left[\mathrm{S}_{\mathrm{f}} 0-20\right]$; and $d=1.063-1.21$ $\mathrm{g} / \mathrm{ml})$. According to currently accepted nomenclature, these fractions are now 


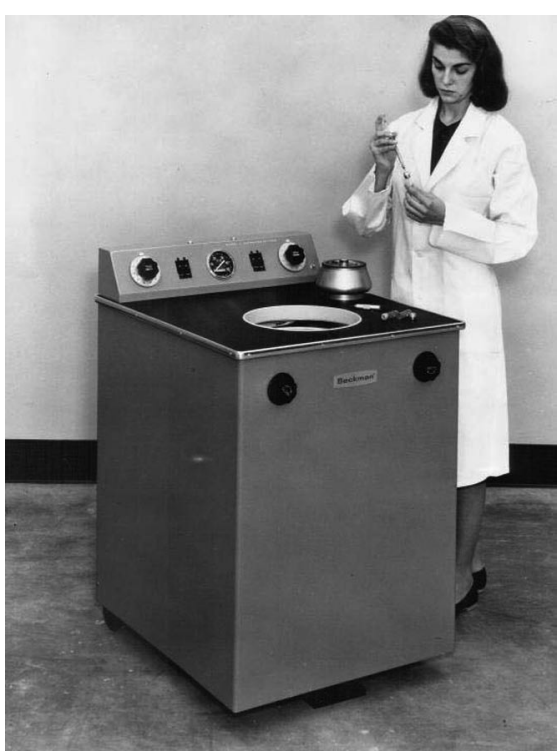

Figure 2

Spinco Model L preparative ultracentrifuge used in the paper by Havel et al. (1). This ultracentrifuge was employed almost exclusively for lipoprotein isolation by early lipoprotein researchers. There were more than 3000 Model Ls sold. Isolation of lipoproteins typically was carried out by centrifugation at $105,000 \mathrm{~g}$ for 20 to 22 hours (1). Image courtesy of Beckman Coulter Inc.

called VLDLs, IDLs, LDLs, and HDLs, respectively. These workers' early proposal that $\mathrm{S}_{\mathrm{f}}$ 12-20 lipoproteins (IDLs) are uniquely atherogenic lipoproteins has not stood the test of time, but some investigators still believe that, on a molar basis, IDL is more atherogenic than LDL, as Gofman et al. (11) later postulated. Gofman's interest in lipoproteins soon waned, but Lindgren and others maintained a powerful research program at the Donner Laboratory for many years. They elevated preparative ultracentrifugation of lipoproteins to a fine art and identified many subfractions within each of the major lipoprotein fractions. Extensive studies on LDL subfractions are a direct outgrowth of earlier work done at the Donner Laboratory $(12,13)$.

Havel et al. (1) separated plasma lipoproteins into three major classes by ultracentrifugation: $d<1.019 \mathrm{~g} / \mathrm{ml} ; d<$ $1.019-1.063 \mathrm{~g} / \mathrm{ml}$; and $d>1.063$. I recently asked Dick why he and his associates did not call these fractions VLDL, LDL, and HDL, respectively, in their paper. He told me that these names were used routinely in their laboratory, but the editors of the JCI would not allow them to use these abbreviations. The terms did appear in print a year later (14). In a subsequent paper, Havel and his coworkers isolated IDL (15) from VLDL by ultracentrifugation. The method of Havel and his colleagues (1) had two advantages over lipoprotein analysis in the analytical ultracentrifuge. First, Havel et al.'s method was less expensive and time consuming. In the 1950s, an analytical ultracentrifuge cost $\$ 30,000$, a nontrivial sum in those days. This instrument was not widely available. The preparative ultracentrifuge was more affordable and soon became a standard part of all lipoprotein laboratories (Figure 2). Second, isolation of specific lipoprotein fractions by preparative ultracentrifuge allowed for chemical analysis of each fraction. This made possible a detailed study of the composition and structure of each of the lipoprotein fractions. At about the same time, Lindgren et al. (16) developed a similar preparative ultracentrifugal technique, but lipid composition was only approximated by infrared absorption analysis. Subsequent researchers have taken advantage of the procedure of Havel et al. (1) to carry out an untold number of investigations into the characteristics of each lipoprotein and its subfractions.

Although preparative ultracentrifugation has remained the gold standard for lipoprotein research, it proved to be too costly and labor intensive for clinical application. For this reason, simplified approaches to lipoprotein analysis for clinical purposes have been developed. For many years, simple measurements of serum cholesterol and triglycerides were the staple of clinical practice. In fact, an early, large study pitted analytical ultracentrifugal analysis of lipoprotein levels against total cholesterol for case-control association with CHD (17). The results failed to demonstrate the superiority of lipoprotein analysis, but the findings were disputed. A majority interpretation made the case for cholesterol; it was authored by such medical luminaries as Irvin H. Page and Fredrick J. Stare. Gofman and his associates, favoring lipoproteins, were left in a minority position. But in the long run, it has become clear that Gofman, Lindgren, and their colleagues were the true winners in this controversy. Lipoprotein analysis, albeit simplified, has become the standard approach for assessing lipid risk factors for CHD.

A major step toward incorporating lipoproteins into clinical practice was the phenotyping system for lipoprotein disorders developed in the laboratory of Donald Fredrickson at NHLBI. This system used the paper electrophoresis method first published by Lees and Hatch in 1963 (18). Subsequently, Fredrickson, Levy, and Lees classified lipoprotein disorders according to which type of lipoprotein was present in excess: chylomicrons (type 1 hyperlipoproteinemia); $\beta$-lipoproteins (LDL) (type 2); pre- $\beta$-lipoproteins (VLDL) (type 4); broad$\beta$-lipoproteins (VLDL remnants) (type 3); and combinations of elevations (19). Type $2 \mathrm{~b}$ consisted of excess LDL+VLDL and type 5 of high VLDL+chylomicrons. This system was widely adopted by clinicians in no small part due to successful marketing of the approach by the NHLBI group. In fact, the phenotyping system introduced the medical world to the concept of lipoprotein disorders and thus is a substantial contribution. It also provided some guidance for treatment of lipoprotein disorders, which added rationality to the clinical approach to the various lipoprotein disorders. A detailed history of the era of lipoprotein phenotyping has been written by Fredrickson (20).

From the clinical viewpoint, a major advance was made with the discovery of Burstein that LDL, IDL, and VLDL can be precipitated with polyanions such as heparin (21). Through the use of heparinmanganese solutions, it became possible to obtain a quantitative separation of these lipoproteins from HDL. This allowed for direct chemical analysis of HDL cholesterol. Thereafter, William Friedewald et al. (22) demonstrated that serum LDL cholesterol can be approximated by a formula without the need for preparative ultracentrifugation. The Friedewald equation is as follows: LDL cholesterol $=$ total cholesterol - HDL cholesterol - triglyceride/5.

This method for estimating LDL cholesterol became known as " $\beta$-estimation." The Friedewald equation has become the standard clinical approach for estimating LDL cholesterol. In fact, Friedewald LDL cholesterol includes LDL+IDL cholesterol. Some investigators still believe that research on human lipoproteins should employ preparative ultracentrifugal separation of lipoproteins for more accurate measurements of LDL cholesterol. Yet the ultracentrifugal method for more accurate LDL cholesterol, called " $\beta$-quantification," also includes IDL. This is because the standard ultracentrifugation run isolates lipoproteins of $d<1.006 \mathrm{~g} / \mathrm{ml}$, which consist only of VLDL. The $\beta$-quantification method was employed in the large Lipid Research Clinics Coronary Primary Prevention Trial (LRC-CPPT) $(23,24)$. The 
LRC program provided a wealth of information about the levels of the different lipoproteins in the United States population. These population data have more recently been superseded by data collected by the National Health and Nutrition Examination Survey (NHANES), in which LDL cholesterol is measured by $\beta$-estimation (22). The primary reason now for using ultracentrifugal $\beta$-quantification is to obtain a more accurate measure of LDL (+IDL) in hypertriglyceridemic plasma. The Freidewald equation for LDL cholesterol breaks down when triglyceride levels are high (22). The preoccupation with LDL in clinical medicine has been based on the view that LDL and IDL are the only significant atherogenic lipoproteins. If this is true, an accurate measurement of these lipoproteins is necessary for evaluating the risk component of lipid disorders.

Early epidemiological studies relating lipoproteins to CHD risk appeared to support the unique atherogenicity of LDL. Because of intercorrelations between VLDL triglycerides and HDL cholesterol, the triglyceride component fell out of being independently predictive of CHD when population data were subjected to multivariate analysis (25). This led to the concept that VLDL is not atherogenic. Still, more recent analyses of population studies have identified triglyceride levels as an independent predictor of risk $(26,27)$. The atherogenicity of VLDL is further supported by other types of investigation. In recent years, Havel has been a proponent of the concept that VLDL+IDL+LDL cholesterol (non-HDL cholesterol) provides a better prediction of CHD risk than does LDL cholesterol alone (28). Non-HDL cholesterol in essence is an indicator of all atherogenic lipoproteins. This concept was also proposed from our laboratory (29). In recent years, belief in the benefit of including VLDL cholesterol in CHD prediction has gained ground, although the idea that LDL cholesterol is uniquely predictive has become so ingrained in the medical community that acceptance of non-HDL cholesterol as the preferred marker or target of therapy has been slow. Recently, however, the National Cholesterol Education Program (30) adopted non-HDL cholesterol as a secondary target of lipid-lowering therapy in patients with hypertriglyceridemia.

With the identification of all of the apolipoproteins of lipoproteins came efforts to redefine lipid disorders in terms of apolipoprotein abnormalities instead of lipid abnormalities. Both Havel and Eder were early leaders in the apolipoprotein field. Among the candidates for clinical measure for prediction of CHD, the strongest case has been made for apoB, the structural protein of LDL, IDL, and VLDL (31). Like non-HDL cholesterol, apoB reflects the concentrations of all atherogenic lipoproteins. Other apolipoproteins associated with these lipoproteins, the apoEs and apoCs, have additionally created enormous interest. A pioneer in this field was Petar Alavpovic, who early recognized the importance of apolipoproteins and who classified lipoproteins into "families" based on their apo content $(32,33)$. Alavpovic has long maintained that the apolipoproteinfamily approach provides a better way to think about lipoprotein metabolism and lipoprotein disorders than a system based on separation of the lipoproteins by physical means, such as that developed by Havel et al. (1). Although the complexity of his family system has precluded its use in routine clinical management, within the research community there has been much sympathy for defining lipoproteins in terms of their apo constituents instead of by their lipid content.

Finally, we must consider where we stand with Eder's primary research interest, HDL. Many epidemiological studies have strongly confirmed the early observation of Eder and his associates that lower levels of HDL are associated with increased risk for CHD. In spite of many theories, the mechanisms of this association have never been fully established. HDL is an integral component of lipoprotein metabolism, and its origins and functions are myriad. This complexity perhaps stands in the way of defining how it is related to CHD. Donner Laboratory investigators (34) early identified subfractions of HDL based on physical separations in the ultracentrifuge. Subsequently, Eder's protégées were able to separate HDL into subfractions by differential precipitation (35) and electrophoretic methods (36). Others have classified HDL fractions according to apo content. Claims have been made that various HDL subfractions differentially correlate with CHD risk. Although the role of HDL in atherogenesis remains somewhat obscure, many current investigators believe that HDL is the lipoprotein of the future. Without doubt, HDL metabolism has become a target for new drug development that holds the promise of augmenting the CHD risk reduction currently afforded by drugs that reduce apoB-containing lipoproteins (30).
Address correspondence to: Scott M. Grundy, Center for Human Nutrition, Department of Clinical Nutrition, Department of Internal Medicine, University of Texas Southwestern Medical Center, 5323 Harry Hines Boulevard, Dallas, Texas 75390-9052, USA. Phone: (214) 648-2890; Fax: (214) 648-4837, E-mail: scott.grundy@utsouthwestern.edu.

1. Havel, R.J., Eder, H.A., and Bragdon, J.H. 1955. The distribution and chemical composition of ultracentrifugally separated lipoproteins in human serum. J. Clin. Invest. 34:1345-1353.

2. Macheboeuf, M. 1930. Recherches sur les phosphoaminolipides et les sterides du serum et du plasma sanguins: I. Entrainement des phospholipids, des sterols et des sterides par les diverses fractions au cours du fractionnement des proteides du serum. Bull. Soc. Chim. Biol. 223:1-99.

3. Bennhold, H. 1932. Ueber die vehikelfunction der serumeiweiskorper. Ergebn. Inn. Med. Kinderheilkd. 42:273-375.

4. Cohn, E.J., et al. 1946. Preparation and properties of serum and plasma proteins: IV. System for separation into fractions of protein and lipoprotein components of biological tissues and fluids. J. Am. Chem. Soc. 68:459-475.

5. Blix, G., Tiselius, A., and Svensson, H. 1941. Lipids and polysaccharides in electrophoretically separated blood serum proteins. J. Biol. Chem. 137:485-494.

6. Pedersen, K.O. 1945. On a low-density lipoprotein appearing in normal human plasma. J. Phys. Colloid Chem. 51:156-163.

7. Gofman, J., Lindgren, F., and Elliott, H. 1949. Ultracentrifugal studies of lipoproteins of human serum. J. Biol. Chem. 179:973-978.

8. Gofman, J., et al. 1950. The role of lipids and lipoproteins in atherosclerosis. Science. 111:166-171.

9. Lindgren, F.T., Elliott, H.A., and Gofman, J.W. 1951. Thte ultracentrifugal characterization and isolation of human blood lipids and lipoproteins, with application to the study of atherosclerosis. J. Phys. Colloid Chem. 55:80-93.

10. De Lalla, O.F., and Gofman, J.W. 1954. Ultracentrifugal analysis of serum lipoproteins. In Methods of biochemical analysis. Volume 1. D. Glick, editor. Wiley. New York, New York, USA. 459-478.

11. Gofman, J.W., Glazier, F., Tamplin, A., Strishower, B., and De Lalla, O. 1954. Lipoproteins, coronary heart disease and atherosclerosis. Physiol. Rev. 34:589-607.

12. Krauss, R.M., and Burke, D.J. 1982. Identification of multiple subclasses of plasma low density lipoproteins in normal humans. J. Lipid Res. 23:97-104.

13. Krauss, R.M. 1995. Dense low density lipoproteins and coronary artery disease. Am. J. Cardiol. 75:53B-57B.

14. Havel, R.J. 1956. Evidence for the participation of lipoprotein lipase in the transport of chylomicrons. In Third International Conference on Biochemical Problems of Lipids: the Blood Lipids and the Clearing Factor. July 26-28, 1956. Brussels, Belgium. 265-273.

15. Baxter, J.H., Goodman, H.C., and Havel, R.J. 1960. Serum lipid and lipoprotein alterations in nephrosis. J. Clin. Invest. 39:455-465.

16. Lindgren, F.T., Nichols, A.V., and Freeman, N.K. 1955. Physical and chemical composition studies on the lipoproteins of fasting and heparinized human sera. J. Phys. Chem. 59:930-938.

17. The Technical Group and Committee on Lipoproteins and Atherosclerosis. 1956. Evaluation of serum lipoprotein and cholesterol measurements as predictors of clinical complications of atherosclerosis. Circulation. 14:691-741.

18. Lees, R.S., and Hatch, F.T. 1963. Sharper separa- 
tion of lipoprotein species by paper electrophoresis in albumin-containing buffer. J. Lab. Clin. Med. 61:518-528.

19. Fredrickson, D.S., Levy, R.I., and Lees, R.S. 1967. Fat transport in lipoproteins: An integrated approach to mechanisms and disorders [review]. N. Engl. J. Med. 276:148-156.

20. Fredrickson, D.S. 1993. Phenotyping. On reaching base camp (1950-1975). Circulation. 87(Suppl. 4): III1-III15.

21. Burstein, M., and Samaille, J. 1958. Determination of serum beta-lipoproteins after selective precipitation by heparin. Presse Med. 66:974-975.

22. Friedewald, T., Levy, R.I., and Frederickson, D.S 1972. Estimation of the concentration of lowdensity lipoprotein cholesterol in plasma, without use of the preparative ultracentrifuge. Clin. Chem. 6:499-503.

23. [Anonymous]. 1984. The Lipid Research Clinics Coronary Primary Prevention Trial results. I. Reduction in incidence of coronary heart disease. JAMA. 251:351-364.

24. [Anonymous]. 1984. The Lipid Research Clinics Coronary Primary Prevention Trial results. II. The relationship of reduction in incidence of coronary heart disease to cholesterol lowering.
JAMA. 251:365-374.

25. Hulley, S.B., Rosenman, R.H., Bawol, R.D., and Brand, R.J. 1980. Epidemiology as a guide to clinical decisions. The association between triglyceride and coronary heart disease. N. Engl. J. Med. 302:1383-1389.

26. Austin, M.A., Hokanson, J.E., and Edwards, K.L. 1998. Hypertriglyceridemia as a cardiovascular risk factor. Am. J. Cardiol. 81:7B-12B.

27. Assmann, G., Schulte, H., Funke, H., and von Eckardstein, A. 1998. The emergence of triglycerides as a significant independent risk factor in coronary artery disease. Eur. Heart J. 19(Suppl. M):M8-M14.

28. Frost, P.H., and Havel, R.J. 1998. Rationale for use of non-high-density lipoprotein cholesterol rather than low-density lipoprotein cholesterol as a tool for lipoprotein cholesterol screening and assessment of risk and therapy. Am.J. Cardiol. 81:26B-31B.

29. Garg, A., and Grundy, S.M. 1990. Management of dyslipidemia in NIDDM [review]. Diabetes Care. 13:153-169.

30. National Cholesterol Education Program. 2002. Third Report of the National Cholesterol Education Program (NCEP) Expert Panel on Detection, Evaluation, and Treatment of High Blood Choles- terol in Adults (Adult Treatment Panel III): final report. Circulation. 106:3143-3421.

31. Sniderman, A.D. 2002. How, when, and why to use apolipoprotein B in clinical practice. Am. J. Cardiol. 90:48i-54i.

32. Alaupovic, P. 1991. Apolipoprotein composition as the basis for classifying plasma lipoproteins. Characterization of apoA- and apoB-containing lipoprotein families. Prog. Lipid Res. 30:105-138.

33. Alaupovic, P. 1996. Significance of apolipoproteins for structure, function, and classification of plasma lipoproteins. Meth. Enzymol. 263:32-60.

34. De Lalla, O.F., Elliott, H.A., and Gofman, J.W. 1954. Ultracentrifugal studies of high-density serum lipoproteins in clinically healthy adults. Am. J. Physiol. 179:333-337.

35. Gidez, L.I., Miller, G.J., Burstein, M., Slagle, S., and Eder, H.A. 1982. Separation and quantitation of subclasses of human plasma high density lipoproteins by a simple precipitation procedure. J. Lipid Res. 23:1206-1223.

36. Asztalos, B.F., Sloop, C.H., Wong, L., and Roheim, P.S. 1993. Two-dimensional electrophoresis of plasma lipoproteins: recognition of new apo A-Icontaining subpopulations. Biochim. Biophys. Acta. 1169:291-300.

\title{
Endothelial cell culture: beginnings of modern vascular biology
}

\author{
Ralph L. Nachman ${ }^{1}$ and Eric A. Jaffe ${ }^{2}$ \\ 1Department of Medicine, Weill Medical College of Cornell University, New York, New York, USA. \\ ${ }^{2}$ Department of Medicine, Interfaith Medical Center, Brooklyn, New York, USA.
}

\begin{abstract}
Endothelial cells derived from human umbilical veins were first successfully cultured in vitro in 1973. Weibel-Palade bodies and the von Willebrand factor antigen were used as morphological, immunohistochemical, and functional markers to unequivocally identify the cells. These landmark studies helped initiate the growth of modern vascular biology.
\end{abstract}

It was a warm sunny afternoon late in the spring of 1969 when one of us (Nachman) spent an hour in the office of a renowned cell biologist discussing why his laboratory wanted to study the biology of endothelial cells. Nachman tried to convey the conviction that this had to be the key to understanding how the blood vessel wall worked. Despite his enthusiasm, the essence of the response received was: "You are probably dealing with the inner tube of a tire and, in fact, if you can grow them in culture, you will probably end up with a nondescript fibroblast. Stick to platelets and blood coagulation.” Lord Adrian Florey apparently had the same attitude, referring to

Conflict of interest: The authors have declared that no conflict of interest exists.

Citation for this article: J. Clin. Invest. 114:1037-1040 (2004). doi:10.1172/JCI200423284.

endothelial cells as "a sheet of nucleated cellophane” $(1,2)$. Fortunately, we ignored the advice $(3,4)$ as well as the literature.

\section{Figure 1}

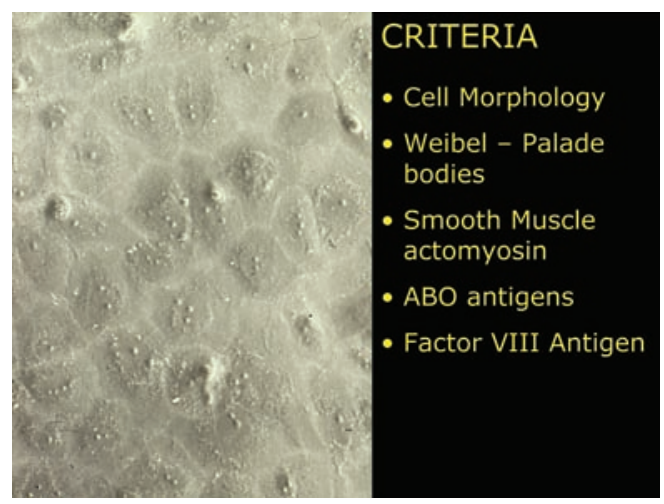

Summary slide presented at the plenary session of the $1974 \mathrm{ASCl}$ annual meeting in Atlantic City showing the first cultured endothelial cells and the criteria used to identify them.

The late 1960 s and early 1970 s were particularly exciting times to be involved in studying the biology of hemostasis. Explosive new ideas were revolutionizing the concepts of blood coagulation physiology and biochemistry $(5,6)$. At the same time, the role of the circulating platelet as the major player in primary hemostasis, leading to the arrest of bleeding, and the paradigm of thrombo-

Investigation http://www.jci.org Volume 114 Number 8 October 2004

1037 